\title{
STEREOCHEMISTRY OF $C$-METHYLATION IN THE BIOSYNTHESIS OF RHODODENDRIN IN ALNUS AND BETULA
}

\author{
Martina Kischies and Meinhart H. ZenK \\ Lehrstuhl für Pflanzenphysiologie, Ruhr-Universität Bochum, D 4630 Bochum, West Germany
}

(Received 12 December 1977)

Key Word Index , Betula alba; Alnus glutinosa; Betulaceae; cinnamic acid pathway; $C$-methylation; stereochemistry; rhododendrin; phenylpropanoid.

\begin{abstract}
Using differently labelled precursors, it was established that rhododendrin (3-(4-hydroxyphenyl)-1methylpropyl- $\beta$-D-glucopyranoside) is formed through the phenylpropane pathway via $p$-coumaryl alcohol, dihydro$p$-coumaryl alcohol and $C$-methylation of the $\gamma$-C-atom of the $\mathrm{C}_{6}-\mathrm{C}_{3}$ unit with methionine supplying the methyl group. It was demonstrated that the pro- $(S)$-hydrogen atom of dihydro-p-coumaryl alcohol is replaced stereospecifically by the methyl group.
\end{abstract}

\section{INTRODUCTION}

Rhododendrin (3-(4-hydroxyphenyl)-1-methylpropyl- $\beta$ D-glucopyranoside) was discovered for the first time in leaves of Rhododendron chrysanthemum [1] and later in the bark of Betula $[2,3]$. More recently its distribution in the genus Rhododendron (Ericaceae) has been surveyed $[4,5]$ and it has been found in Bergenia (Saxifragaceae) [4]. No information regarding the biosynthesis of this interesting phenolic glucoside is available. Rhododendrin and its aglycone rhododendrol may be assumed to be derived from $p$-coumaric acid via dihydrop-coumaryl alcohol and subsequent $C$-methylation of the $\gamma$-C-atom of the phenylpropyl alcohol. This latter reaction would create a chiral center with unknown stereochemical configuration. The availability of prochiral tritium labelled cinnamyl alcohols [6] of known stereochemistry [7] and high configurational purities make it possible to attempt to study the steric course of the assumed $C$-methylation and furthermore to clarify the relative configuration of rhododendrol and its glucoside.

\section{RESULTS AND DISCUSSION}

A survey of the biosynthetic capacity of different rhododendrin-containing species was made in order to select the most suitable experimental material. Rhododendron chrysanthemum as well as Bergenia speciosa proved to be unsuitable for incorporation experiments with labelled precursors due to low metabolic rate or seasonal variations. However, 9-month-old seedlings of Betula alba proved to be well suited and material was available all the year round. Another member of the Betulaceae, Alnus glutinosa, was found to contain rhododendrin and this plant also proved to be suitable for incorporation experiments at the 9 month seedling stage. The occurrence of rhododendrin in Alnus and Betula was established by TLC ub 5 solvents, UV spectroscopy and conversion to rhododendrol by $\beta$-glucosidase followed by subsequent GC/MS of the aglycone. Rhododendrin was present
Table 1. Incorporation of potential ${ }^{14} \mathrm{C}$ and ${ }^{3} \mathrm{H}$ labelled precursors into rhododendrin of Alnus glutinosa and Betula alba

\begin{tabular}{|c|c|c|c|c|c|}
\hline Precursor applied & ( $\mu \mathrm{mal})$ & $\begin{array}{c}\text { Total } \\
\text { act. } \\
\left(\mathrm{dpm} \times 10^{6}\right)\end{array}$ & $\begin{array}{l}\text { Isolated } \\
(\mu \mathrm{mol})\end{array}$ & $\begin{array}{l}\text { Rhodo- } \\
\text { dendrin } \\
\text { Sp. act } \\
\text { (dpm/ } \\
\text { Jmol) }\end{array}$ & $\begin{array}{c}\text { Incor- } \\
\text { poration } \\
(\%)\end{array}$ \\
\hline$p$-coumaric ac1d $\left[\mathrm{U}-{ }^{1+} \mathrm{C}\right]^{*}$ & 0.05 & 5.55 & 1.24 & 8309 & 0.34 \\
\hline $\begin{array}{l}p \text {-coumaric acid }\left[\mathrm{U}-{ }^{14} \mathrm{C}\right] \dagger \\
\text { dihydro-p-coumaric aced }\end{array}$ & 005 & 5.55 & 1.04 & 10673 & 0.22 \\
\hline & 0.04 & 4.22 & 1.90 & 13089 & 1.32 \\
\hline$\left[\mathrm{U}-{ }^{14} \mathrm{C}\right] \dagger$ & 0.03 & 255 & 160 & 20558 & 0.78 \\
\hline$p$-coumaryl alcohol $\left[\mathrm{U}^{14} \mathrm{C}\right]^{*}$ & 0.07 & 015 & 1.28 & 941 & 125 \\
\hline $\begin{array}{l}\text { dihydro-p-coumaryl alcohol } \\
{\left[\mathrm{U}-{ }^{14} \mathrm{C}\right]^{*}} \\
\text { dihydro-p-coumaryl alcohol }\end{array}$ & 020 & 0.19 & 1.27 & 1466 & 0.98 \\
\hline $\begin{array}{l}{\left[\mathrm{U}-{ }^{14} \mathrm{C}\right] \dagger} \\
\mathrm{L}-\mathrm{meth}^{-}\end{array}$ & $\begin{array}{l}0.07 \\
1.00\end{array}$ & $\begin{array}{c}015 \\
2.22 \times 10^{2}\end{array}$ & $\begin{array}{l}1.40 \\
2.00\end{array}$ & $\begin{array}{r}300 \\
85665\end{array}$ & $\begin{array}{l}028 \\
008\end{array}$ \\
\hline
\end{tabular}

* Alnus glutinosa $\uparrow$ Betula alba

at $0.15 \%$ in $A$. glutinos $a$ and $0.30 \%$ in $B$. alba based on dry matter. In order to establish the pathway for the biosynthesis of rhododendrin, a series of ${ }^{14} \mathrm{C}$ - or ${ }^{3} \mathrm{H}$ labelled precursors were fed to young terminal shoots of both $A$. glutinosa and $B$. alba and the degree of incorporation was measured. As shown in Table 1, both pcoumaric acid and its dihydro derivative were satisfactorily incorporated into the glucoside. The same holds true for both coumaryl alcohol and dihydrocoumaryl alcohol. Thus the phenylpropane pathway is involved in the biosynthesis of rhododendrin. From the incorporation data it is, however, not possible to distinguish between pathway A or B in the Scheme 1 . Surprisingly both the acid and the alcohol containing either a double bond between the $\alpha$ - and $\beta$-C-atom of the side chain or the fully hydrogenated derivatives are incorporated approximately equally. This shows that the enzymes involved in the hydrogenation of the double bond of either $p$-coumaric acid or its alcohol exhibit a considerable lack of specificity. The assumed precursor of rhododendrin, dihydro-p-coumaryl alcohol, may 


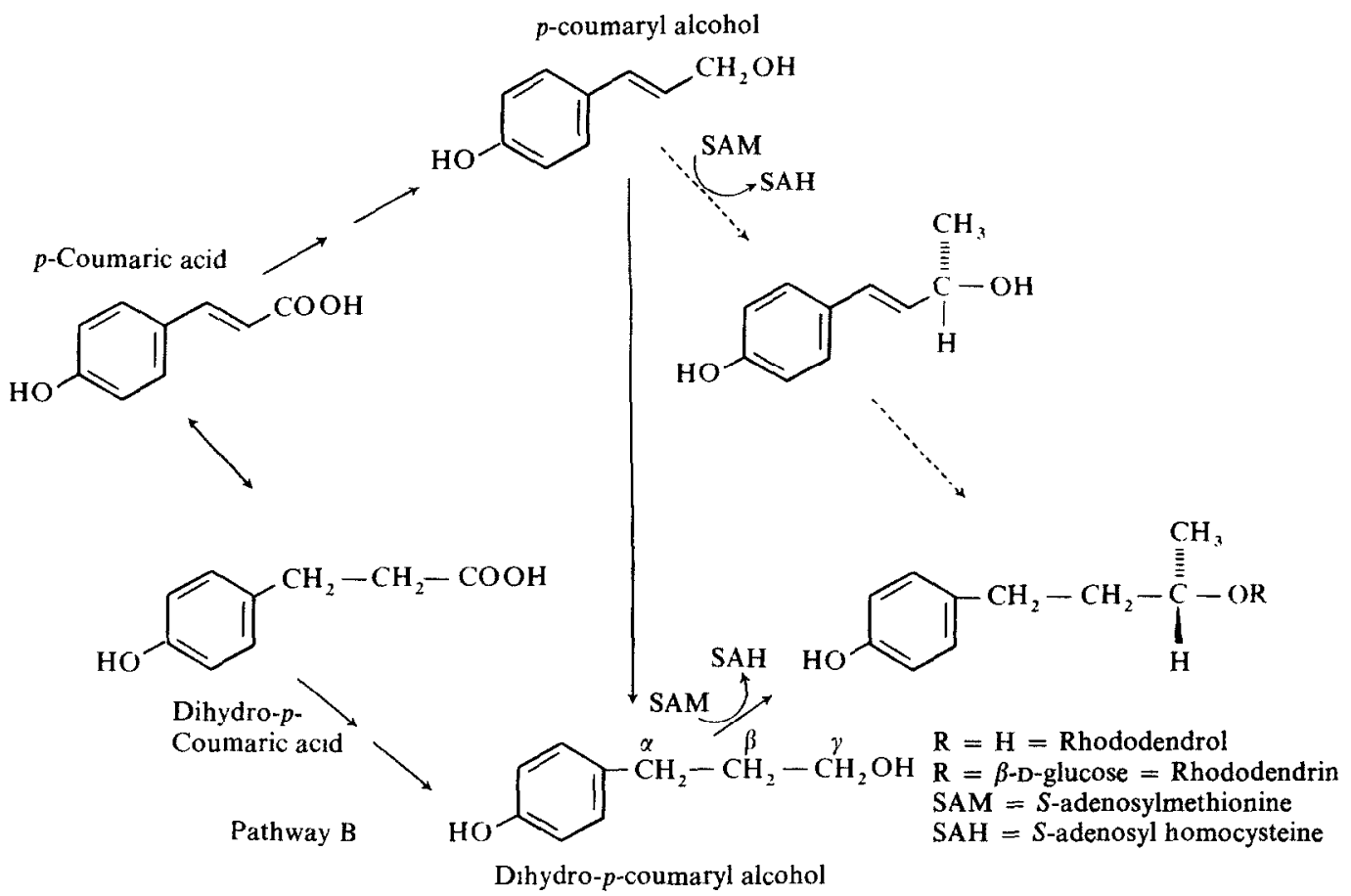

Scheme 1. Proposed pathway for the biosynthesis of rhododendrin.

therefore be formed in vivo either by reduction of $p$ coumaric acid to dihydro-p-coumaric acid followed by activation and reduction of the carboxyl group [8] or by reduction of $p$-coumaryl alcohol. Thus the exact mechanism can only be decided by using cell-free systems. The incorporation of the $\mathrm{C}_{6}-\mathrm{C}_{3}$ units into rhododendrin accounts for the biosynthetic origin of six of the total of seven required carbon atoms. In order to determine the origin of the missing carbon, L-methionine $\left(-\mathrm{C}^{3} \mathrm{H}_{3}\right)$ was supplied to the shoot of $A$. glutinos $a$ and an incorporation of $0.08 \%$ was observed (Table 1). In order to prove that the methyl group of methionine was incorporated into the methyl group of the glucoside, rigorously purified rhododendrin $(51339 \mathrm{dpm})$ was diluted and subjected to Kuhn-Roth oxidation. The resulting acetate, which is derived from the methyl group and the adjacent carbon atom carrying the alcohol function (corresponding to $\gamma$-C of dihydro-p-coumaryl alcohol). contained $506 \mathrm{dpm} / \mu \mathrm{mol}$ (theoretically $555 \mathrm{dpm} / \mu \mathrm{mol}$ ) and thus this compound carried $91 \%$ of the required radioactivity. This proves that the methyl group of rhododendrin is derived from the methyl group of methionine. Thus the original hypothesis on the biosynthesis of rhododendrin was confirmed in that dihydro$p$-coumaryl alcohol is $C$-methylated at the alcohol function of the phenylpropyl derivative. The possibility that the $C$-methylation occurs at the level of the $p$ coumaryl alcohol and that the methylated propene derivative is subsequently reduced is unlikely but cannot be excluded.

If there is a stereospecific step involved in the course of the methylation, clearly one hydrogen atom of the alcohol group, either the pro- $R$ or the pro- $S$, has to be removed and replaced by the methyl group derived from $S$-adenosylmethionine. In order to prove this reaction and to establish its stereochemical course, if any, tritium labelled $R$ - and $S$ - $p$-coumaryl alcohol and dihydro-p-coumaryl alcohol were synthesized according to known methods [6]. The introduction of the label was achieved using the highly stereospecific horse liver alcohol dehydrogenase system [7].

In a preliminary experiment doubly labelled $(R, S)-$, $\left(\gamma-{ }^{3} \mathrm{H}\right)-\left[\mathrm{U}-{ }^{14} \mathrm{C}\right]-p$-coumaryl alcohol was fed to a rigorously growing shoot of $A$. glutinosa. The ${ }^{3} \mathrm{H} /{ }^{14} \mathrm{C}$ ratio of the precursor was $18.31: 1$. The labelled rhododendrin formed in this experiment was isolated, purified and was found to have a ${ }^{3} \mathrm{H} /{ }^{14} \mathrm{C}$ ratio of $10.30: 1$. This result corresponds to a loss of about $45 \%$ of the tritium label (no isotope effects were taken into consideration) which is in accordance with the assumption that one of the hydrogen atoms of the $\gamma$-C-atom is replaced by the methyl group introduced from methionine. The crucial experiment consisted in feeding the two pure labelled enantiomers to the plants. It was observed in both $A$ lnus as well as in Betula that the $(R)$-p-coumaryl alcohol was incorporated into rhododendrin to an extent of $2.7 \%$

Table 2. Incorporation of $(R)-\left(\gamma-{ }^{3} \mathrm{H}\right)$ - and $\left[\mathrm{U}-{ }^{14} \mathrm{C}\right]$ - as well as $(S)-\left(\gamma-{ }^{3} \mathrm{H}\right)$ - and $\left[\mathrm{U}-{ }^{14} \mathrm{C}\right]$-dihydro-p-coumaryl alcohol into thododendrin in Alnus glutinosa and Betula alba

\begin{tabular}{|c|c|c|c|c|c|c|}
\hline Plant species & Precursor & $\begin{array}{c}{ }^{3} \mathbf{H} /{ }^{14} \mathrm{C} \\
\text { ratio }\end{array}$ & $\begin{array}{c}\text { Incorpora } \\
{ }^{3} \mathbf{H}\end{array}$ & $\begin{array}{l}\text { Rhodod } \\
\text { atron }(\%) \\
\left.{ }^{14} \mathrm{C}\right)\end{array}$ & $\begin{array}{l}\text { dendrin } \\
{ }^{3} \mathrm{H} /{ }^{14} \mathrm{C} \\
\text { ratio }\end{array}$ & $\begin{array}{c}\text { Loss of } \\
{ }^{3} \mathbf{H} \\
(\%)\end{array}$ \\
\hline A. glutinosa & $\left\{\begin{array}{l}(R)-\left(\gamma^{3} \mathrm{H}\right) /\left(\mathrm{U}^{-14} \mathrm{C}\right) \\
(\mathrm{S})-\left(\gamma-{ }^{3} \mathrm{H}\right) /\left(\mathrm{U}^{14}{ }^{14} \mathrm{C}\right)\end{array}\right.$ & $\begin{array}{r}9861 \\
24001\end{array}$ & $\begin{array}{l}096 \\
008\end{array}$ & $\begin{array}{l}0.98 \\
096\end{array}$ & $\begin{array}{l}9591 \\
235 \cdot 1\end{array}$ & $\begin{array}{r}27 \\
902\end{array}$ \\
\hline B. $a l b a$ & $\left\{\begin{array}{l}(R)-\left(\gamma^{3} \mathrm{H}\right) /\left(\mathrm{U}^{-14} \mathrm{C}\right) \\
(S)-\left(\gamma-{ }^{3} \mathrm{H}\right) /\left(\mathrm{U}^{-14} \mathrm{C}\right)\end{array}\right.$ & $\begin{array}{r}6181 \\
12881\end{array}$ & $\begin{array}{l}0.23 \\
0.09\end{array}$ & $\begin{array}{l}022 \\
0.28\end{array}$ & $\begin{array}{l}6.261 \\
3171\end{array}$ & $\begin{array}{c}0 \\
7539\end{array}$ \\
\hline
\end{tabular}


<smiles>[2H]C([18OH])C=Cc1ccc(O)cc1</smiles>

Dihydro-p-coumaryl alcohol<smiles>C=Cc1ccc(O)cc1</smiles>

$(R)-\left[\gamma-{ }^{3} \mathrm{H}\right]$<smiles>[R17]O[C@@H](C)[C@@H](C)O</smiles>

Rhododendrin<smiles>C[C@@H](O)Cc1ccc(O)cc1</smiles>

$\mathrm{R}=\beta$-D-glucose

Scheme 2. Biosynthetic incorporation of $(R)-\left(\gamma_{-}{ }^{3} \mathrm{H}\right)$ - and $(S)-\left(\gamma-{ }^{3} \mathrm{H}\right)$-dihydro-p-coumaryl alcohol into rhododendrin in Alnus glutinosa and Betula alba.

and $5.4 \%$ respectively, while the (S)-enantiomer was incorporated only to an extent of $0.08 \%$ and $0.8 \%$ respectively. The much lower incorporation of the (S)-enantiomer suggested that it is the pro-(S) hydrogen atom which is replaced by methylation. However, final proof that this assumption is correct came from an experiment using ${ }^{3} \mathrm{H} /{ }^{14} \mathrm{C}$ doubly labelled pure enantiomers of both $p$-coumaryl alcohol and dihydro-pcoumaryl alcohol.

The results of the double label experiment are shown in Table 2. This clearly shows which of the $\gamma$-hydrogen atoms is replaced. Invariably in both plants the pro$R$-hydrogen atom of dihydroxy-coumaryl alcohol was completely retained and the pro-S-hydrogen atom was largely lost.

These experiments prove that during the enzymatically catalyzed methylation of the $\gamma$-C-atom of either $p$ coumaryl alcohol or dihydro-p-coumaryl alcohol the pro-S hydrogen atom is stereospccifically removed according to Scheme 2 .

\section{EXPERIMENTAL}

Plant material. A. glutinosa and B. alba was purchased from the firm Bornträger (Offstein, Germany). The plants were grown in a Phytotron chamber with a photoperiod of $16 \mathrm{hr}$ day $(2500 \mathrm{~lx}), 8 \mathrm{hr}$ night and a $23^{\circ}-18^{\circ}$ day-night temperature cycle at $70-75 \%$ rel. hum. The plants were used at an age of 9 months.

Feeding and isolation procedure. The labelled compounds were fed through the cut end of an excised young terminl shoot (ca $4 \mathrm{~cm}$ in height). The tracer was usually allowed to be metabolized for $24 \mathrm{hr}$. Subsequently the shoot was cut into $0.5 \mathrm{~cm}$ pieces and exhaustively extracted with boiling $80 \% \mathrm{EtOH}$. The extract was purified first by preparative layer $(1.5 \mathrm{~mm})$ chromatography in $\mathrm{CHCl}_{3} \cdot \mathrm{MeOH}(4: 1)$ and then by TLC in $\mathrm{C}_{6} \mathrm{H}_{6}-\mathrm{EtOH}(8: 2) ; \mathrm{CHCl}_{3}$-EtOH (7.7:1): EtOAc-MeCOEt$\mathrm{HCOOH}-\mathrm{H}_{2} \mathrm{O}(5: 3: 1: 1: 1)$, rhododendrin $R_{f}$ values $0.4 ; 0.60$; $0.25: 0.72$, respectively. The $\varepsilon_{278}(\mathrm{MeOH})$ was $1.59 \times 10^{6}$ $\mathrm{M}^{-1} \mathrm{~cm}^{-1}$. Rhododendrin was converted to rhododendrol by incubation with $\beta$-glucosidase (Boehringer), the aglycone was then ether extracted from the incubation mixture and purified by TLC using $\mathrm{CHCl}_{3}-\mathrm{EtOH}(7.7: 1)$. The $R$ was 0.6 . Both the glycoside and the aglycone gave a red coloration on spraying with conc $\mathrm{H}_{2} \mathrm{SO}_{4}$. Rhododendrol was further characterised by GLC $(3 \%$ SE 30 on supelcoport, He $36 \mathrm{ml} / \mathrm{min}$ programme $\left.100-200^{\circ}, 10^{\circ} / \mathrm{min}\right)$. The rhododendrol retention time was $6.7 \mathrm{~min}$ and $\mathrm{MS} \mathrm{m} / \mathrm{e}: 166\left(\mathrm{M}^{+}\right), 148\left(\mathrm{M}-\mathrm{H}_{2} \mathrm{O}\right), 133$, 107.

Synthesis and degradation of labelled compounds. [U- $\left.{ }^{14} \mathrm{C}\right]-\mathrm{L}-$ tyrosine was deaminated using PAL to $p$-coumaric acid which was then hydrogenated $\left(\mathrm{Pd} / \mathrm{H}_{2}\right)$ to yield dihydro-p-coumaric acid. $\left[\mathrm{U}-{ }^{14} \mathrm{C}\right]$-p-coumaric acid was transformed by standard methods into $p$-coumaryl alcohol via acetyl-p-coumaric acid, acetyl-p-coumaryl chloride reduction, and alkaline hydrolysis. The labelled alcohol was further hydrogenated to dihydro- $p$ coumaryl alcohol $\left(\mathrm{Pd} / \mathrm{H}_{2}\right)$. The stereospecifically labelled alcohols were synthesized to the corresponding coniferyl alcohols [6]. $(R, S)-\left(\gamma-{ }^{3} \mathrm{H}\right)$-p-coumaryl alcohol was synthesized from $p$-coumaryl aldehydes by reduction with $\mathrm{NaBH}_{3} \mathrm{~T}$ (yield via ${ }^{3} \mathrm{H} 22.4 \%$; sp. act. $\left.239 \mu \mathrm{Ci} / \mu \mathrm{mol}\right)$. (S) $-\left(\gamma^{3}{ }^{3} \mathrm{H}\right)-p$ coumaryl alcohol $(25 \%$ yield, sp. act. after dilution $28 \mu \mathrm{Ci} / \mu \mathrm{mol})$ $p$-coumaryl aldehyde (yield $45 \%$ sp. act. $119.5 \mu \mathrm{Ci} / \mu \mathrm{mol}$ ). $(R)-\left(\gamma-{ }^{3} \mathrm{H}\right)-p$-coumaryl alcohol via ${ }^{3} \mathrm{H}$-cyclohexanol [7] (yield $9.2 \%$ sp. act. $1.12 \mathrm{mCi} / \mu \mathrm{mol})$. All labelled $p$-coumaryl alcohol species were hydrogenated $\left(\mathrm{Pd}: \mathrm{H}_{2}\right)$ at $70-80 \%$ yield into the correspondingly labelled dihydro-p-coumaryl alcohol with unchanged sp. act. (MS m/e: $\left.152\left(\mathbf{M}^{+}\right), 134\left(\mathbf{M}-\mathrm{H}_{2} \mathrm{O}\right), 107,77\right)$. Kuhn-Roth degradation was conducted under conditions given in [9].

Acknowledgements-We thank Prof. H. Thieme, Leipzig, for a generous gift of pure rhododendrin, Dr. G. Wilson, Dublin, 
for his help in the preparation of the English version of this manuscript and the 'Deutsche Forschungsgemeinschaft' for financial support.

\section{REFERENCES}

1. Archangelsky, K. (1901) Arch. Exp. Path. Pharmak. 46, 313.

2. Sosa, A. (1933) Chem. Zentralblatt II, 1193.

3. Kim, K.-U. (1942) J. Pharm. Soc. Japan 62, 455.

4 Thieme, H and Winkler. H. J. (1969) Pharmazie 24. 703:
Thieme, H., Walewska, E. and Winkler, H. J. (1969) Pharmazie 24, 648 .

5. Harborne, J. B. and Williams, C. A. (1971) Phytochemistry 10, 2727.

6. Klischies, M., Stöckigt, J. and Zenk, M. H. (1978) Phytochemistr! (in press).

7. Battersby, A. R., Staunton, J. and Wiltshire, H. R. (1975) J. Chem. Soc. Perkin Trans. 11156.

8. Gross, G. G., Stöckigt, J., Mansell, R. I. and Zenk, M. H. (1973) FEBS Lett. 31, 283.

9. Durand, R. and Zenk, M. H. (1974) Phytochemistry 14, 1483. 